\title{
Impact of Information on Northeastern U.S. Consumer Willingness to Pay for Aronia Berries
}

\author{
Omer Hoke ${ }^{1}$ \\ PricewaterhouseCoopers, San Jose, 488 Almaden Blvd \#1800, San Jose, \\ CA 95110
}

\author{
Benjamin Campbell ${ }^{2,4}$ \\ Department of Agricultural and Applied Economics, University of Georgia, \\ 314A Conner Hall, Athens, GA 30602
}

\section{Mark Brand ${ }^{3}$ and Thao Hau ${ }^{1}$ \\ Department of Plant Science and Landscape Architecture, University of Connecticut, Storrs, CT 06269}

Additional index words. local labeling, aronia berry, willingness to pay

\begin{abstract}
Consumption of berries has increased significantly over the past couple of years. As such, producers and retailers are experimenting with new berry varieties to capture market share and increase their profitability. We examine consumer preference and willingness to pay (WTP) for a relatively new-to-market berry (aronia: Aronia mitschurinii Skvortsov et Maitulina) compared with another relatively new berry (black currant: Ribes nigrum L.) as well as more traditional (raspberry: Rubus idaeus L., blueberry: Vaccinium corymbosum L., and blackberry: Rubus fruticosus L.) berries. Given that aronia berries have an astringent/bitter flavor while having high antioxidant levels we investigate how taste and health information impact preference and WTP. Furthermore, we add to the literature by investigating the differences in WTP for locally and nonlocally (regional, the United States, and outside the United States) labeled berries across varying retail outlets (i.e., farmer's markets, farm stands, grocery store). We find that new berries (aronia and black currant) are heavily discounted compared with more traditional berries. Potentially negative taste information (i.e., astringent/bitter flavor) has a negative impact on WTP, whereas positive health information has a positive impact on WTP. The positive effect of health information tends to offset the impact of the negative taste information. With respect to local labeling and retail outlet, locally labeled berries at a farmer's market and farm stand have WTP values similar to locally labeled berries at a grocery store. On the other hand, nonlocally labeled berries sold at a grocery store were discounted compared with locally labeled berries at a grocery store.
\end{abstract}

Berry consumption within the United States has been trending upward over the last decade. According to USDA estimates, consumption of fresh raspberries ( $R$. idaeus), strawberries [Fragaria $\times$ ananassa (Weston) Duchesne ex Rozier (pro sp.)], and blueberries $(V$. corymbosum) have seen continuous growth from 2002 to 2012. During this period, per capita consumption of raspberries, strawberries, and blueberries has increased by

\footnotetext{
Received for publication 22 Sept. 2016. Accepted for publication 13 Dec. 2016.

We gratefully acknowledge funding from a Sustainable Agriculture Research and Education grant, which is funded by the USDA-National Institute of Food and Agriculture. This funding was instrumental in conducting this research effort.

Dr. Hoke's contribution to this paper is a result of his efforts and resources during his time as a Ph.D. student at the University of Connecticut.

${ }^{1}$ Transfer Pricing Associate.

${ }^{2}$ Assistant Professor.

${ }^{3}$ Professor Horticulture.

${ }^{4}$ Corresponding author. E-mail: bencamp@uga. edu.
}

$440 \%, 67 \%$, and $243 \%$, respectively (USDA Economic Research Service, 2014). Further, berries have become one of the leading and fastest growth categories in fresh produce departments (Cook, 2012; The Nielson Company, 2015). As noted in The Wall Street Journal, food companies are seeking out new types of berries to appeal to increased consumer demand (Chaker, 2013). Such berries include aronia (A. mitschurinii), black currant ( $R$. nigrum), bilberry (Vaccinium myrtillus L.), elderberry (Sambucus nigra L.), and goji berry (Lycium barbarum L.). Given the health benefits of berries, especially new varieties, they have received widespread attention in both the academic literature (Lawless et al., 2012; Mohebalian et al., 2012, 2013) and in media coverage, including USA Today, Men's Journal, The Wall Street Journal, and Fox News (Beck, 2014; Chaker, 2013; Fong, 2013; Kilham, 2013).

In particular, aronia berries are gaining popularity within the United States due to their high antioxidant content (Beck, 2014; McKay, 2001). Aronia berries have been commercially grown in European countries since the 1950s (Hannan, 2013). Currently, aronia production is occurring throughout the United States with a majority of production in the Midwest (Everhart, 2011) with increasing production in New England. However, unlike many berries, such as blueberries, raspberries, blackberries, etc., aronia berries have an astringent/bitter flavor which could be a drawback for many consumers. A key potential advantage to aronia berries is their high antioxidant content which is higher than all competing berries. Given the increased demand for healthy local food, especially produce [see popular press articles by DiMartino (2016), Gagliardi (2015), and Kennell (2016)], many U.S. producers are examining the raw berry market and looking for ways to produce and sell aronia berries. In attempting to compete against "sweet" berries, it is essential for aronia producers to understand how taste and health messaging impact consumer WTP.

The main objective of this paper was to evaluate how consumers value a new-tomarket berry (aronia) in contrast to another relatively new berry (black currant), as well as more traditional berries (raspberry, blueberry, and blackberry). Our hypothesis was that aronia and black currant would be less preferred than more traditional berries given they is a higher level of familiarity. As noted by Monroe (1976), brand familiarity is a dominant cue in a consumer's decision process. Even though raspberry, blueberry, and blackberry are not brands, consumers are most likely more familiar with these berries and would most likely choose them over black currant or aronia.

To raise awareness and sales of these new berries, producers and retailers may want to label taste and/or health information to spur interest in new berries, especially given taste is an experience attribute (i.e., evaluated only after the berry is consumed). Clark (1998) noted that taste is an important factor in food choice whereas McFarlane and Pliner (1997) reported that nutritional information can impact willingness to try a novel food. Furthermore, nutritional information can positively impact satisfaction while also impacting food selection (Cranage et al., 2003). Therefore, we examined the impact of potentially negative taste information (aronia berries have an astringent/bitter flavor) and positive health messaging (aronia have a high antioxidant content) on aronia berry preference. We also hypothesized that providing only taste information would decrease WTP for aronia given the astringent/ bitter flavor is often thought of in a negative light (Steiner, 1977). However, we hypothesize that the health information will have a positive impact on WTP since high antioxidant levels and perceived health benefits associated with the antioxidant levels would provide a benefit for which consumers will pay a premium. Roosen et al. (2007) and $\mathrm{Hu}$ et al. (2012) note that health relevant product information can impact consumer choice. Of key interest is whether health information, 
when provided with taste information, can offset any negative WTP associated with the astringent/bitter flavor of aronia. We hypothesize that providing health information (expected positive WTP) in conjunction with taste information (expected negative WTP) will offset WTP to a level that is equivalent to the no information treatment.

In conducting the experiment, we also had a secondary objective to better understand consumer WTP at various retail outlets when berries were labeled as local, regional, United States, or grown outside United States. As noted by $\mathrm{Hu}$ et al. (2009), local labeling can be an important factor in the purchase of blueberries. Furthermore, we were interested in whether WTP differences exist for locally labeled berries sold at either a farmer's market, farm stand, or grocery store. Our hypothesis was that locally labeled berries sold at a farmer's market and farm stand would have a higher WTP than locally labeled berries sold at a grocery store.

\section{Materials and Methods}

To test the objectives aforementioned, an online consumer survey of consumers residing in the Northeastern United States was conducted during the Fall 2013. Using online surveys come with advantages and disadvantages. Several advantages of online surveys compared with other types of surveys include being less expensive, faster, and more accurate data (Cobanoglu et al., 2001; Dillman et al., 2009; McCullough, 1998). A potential downside to Internet surveys is that respondents with no Internet access are generally excluded from the sample. However, $81 \%$ of United States households had access to the Internet in 2012 (World Bank, 2013). Further, if our sample is representative of the overall population of the Northeast then we can feel more comfortable with generalizing our results to the overall population.

The sample consisted of 548 completed surveys with participants from the Northeastern United States. (Connecticut, Maine, Massachusetts, New Hampshire, New Jersey, New York, Pennsylvania, Rhode Island, and Vermont). Survey respondents came from the database of Global Marketing Insite, Inc. (GMI). GMI contacted panelists older than 18 years of age from their database by e-mail and provided a link to the survey. If the panelist agreed to participate, then they entered the survey which consisted of three parts. First, respondents were asked to complete a choice experiment (CE). We used a CE to examine consumer behavior and WTP for different berry products with varying attributes. Second, respondents were asked to complete questions about their fresh fruit and berry consumption. Finally, respondents' were asked demographic questions such as age, gender, state, education, income, number of adults/ children in the household, etc. Response rate for the survey was $85 \%$.

The descriptive statistics associated with the sample can be found in Table 1. The median household income for the sample was $\$ 65,000$, which was slightly higher than the median income for households in the Northeast, \$60,131 (U.S. Census Bureau, 2014). The median age of our sample was 55 , which is higher than the median age in the Northeast at 39 years (U.S. Census Bureau, 2011). However, $25 \%$ of the Northeast United States population are less than 18 years of age. So, when adjusting the U.S. Census age estimates for greater than 18 years of age only, which is consistent with our sample, our sample age is similar to the Northeast population of 47 years. Similar to the Northeast U.S. population, $54 \%$ of our sample were women. Furthermore, $86 \%$ of our sample was Caucasian which is similar to that of the Northeastern population (84\%) (U.S. Census Bureau, 2014). Given that census estimates do not provide standard errors to their estimates, we cannot test whether our sample is statistically different from the Northeast U.S. population.

CE has been used widely in the literature to explore consumers' purchasing behavior (Janssen and Hamm, 2012; Onozaka and McFadden, 2011). In particular, Onozaka and McFadden (2011) use CE to analyze changes in consumer WTP for apples and tomatoes depending on different product labels. CE has also been used widely to examine consumer WTP for local products. For instance, Darby et al. (2008) found that consumer WTP for local goods is independent from values associated with different attributes such as freshness and farm size. With respect to berries, Wang et al. (2016) used a CE to identify consumer segments for strawberries.

The first step in a $\mathrm{CE}$ is to select the attributes (and levels) that are important to consumers in making their decision to purchase. Consulting with industry experts and previous literature, we chose four attributes: berry type, price, production/retail location, and organic production (Table 2). The five berries selected were aronia, black currant, blackberry, blueberry, and raspberry. Blueberry, blackberry and raspberry were selected given their prevalence in the marketplace, whereas black currant and aronia were chosen since they are relatively new to the U.S. market. By comparing black currant and aronia berries within the $\mathrm{CE}$, we can evaluate how two relatively new and unheard of berries compare with each other. It can be difficult for consumers to gauge preference for new or unknown products. However, in a retail outlet consumers will be faced with such decisions, thereby, the CE methodology works well in situations such as this where consumers are faced with a decision of which product to purchase. With respect to prices, we consulted with producers and retailers while also examining prices at various retail outlets. Prices ranged from $\$ 1.99$ to $\$ 5.99$ for a half-pint (eight ounce) container of berries.

Local labeling and location have been shown to be important to the purchase decision. As noted by Shi et al. (2013) and
Carroll et al. (2013), local products can have varying WTP values depending on the store type. Therefore, our location attribute levels were "state name" grown at a farmer's market, "state name" grown at a farm stand, "state name" grown at a grocery store, Northeastern grown at a grocery store, U.S. grown at a grocery store, and grown outside the United States at a grocery store. The "state name" corresponded to the state of residence indicated by the respondent. For instance, a resident of New York would see Farm stand aronia berries for \$3.99/half-pint produced in New York, whereas a Connecticut resident would see Farm stand aronia berries for \$3.99/half-pint produced in Connecticut. Northeastern U.S.-grown and outside U.S.grown berries are not generally sold at farmer's market or farm stand so this option was not included. Organically certified was also included as an attribute given discussions with producers/retailers indicated there was an interest in selling organically produced berries.

Similar to Carroll et al. (2013) and Lim and $\mathrm{Hu}$ (2015), among others, the profiles were created using a D-optimality criterion,

Table 1. Demographics of respondents from a 2013 survey of Northeastern U.S. consumers $(\mathrm{n}=548)$. Age

Median household income 55

Male (\%)

Caucasian (\%) 65,000 46

Education (\%)

High school or less

86.8

Some college/2-year degree

Bachelor's degree

Graduate degree above bachelor's

Table 2. Product attributes and levels used in a choice based experiment of Northeastern U.S. consumers administered during 2013.

\begin{tabular}{ll}
\hline Attribute & \multicolumn{1}{c}{ Levels } \\
\hline Location & $\begin{array}{c}\text { Locally }{ }^{z} \text { grown sold at farmer's } \\
\text { market } \\
\text { Locally }\end{array}$ \\
& Locally grown grown sold at farm stand \\
& store \\
& Northeastern grown sold at \\
& grocery store \\
& U.S. grown sold at grocery store \\
& Grown outside U.S. sold at \\
& grocery store
\end{tabular}

$\begin{array}{cc}\text { Price/8-ounce } & \$ 1.99 \\ \text { container } & \$ 2.89 \\ & \$ 3.99 \\ & \$ 4.59 \\ & \$ 5.29 \\ & \$ 5.99\end{array}$

Berry variety Blueberry

Blackberry

Aronia berry

Raspberry

Black currant

Organic Yes

"For each state "locally" was replaced by the state where the respondent resided. 
see Kuhfeld (2010) for a complete discussion on the criterion. The D-optimal design was constructed in SAS using the program developed by Kuhfeld (2010). Using this criterion we generated 15 choice sets with four product profiles and a "none of the above" option. Before beginning the CE section of the survey, respondents were randomly assigned to an information treatment, taste information, health information, taste/health information, or no information (control). The control group treatment one (T1) had no information provided to them. Treatment two (T2) provided taste information about aronia berries, notably that they have a strong astringent/bitter flavor. Trying to understand consumer reaction to taste information via a survey has both advantages and disadvantages. Optimally, a sensory experiment across a large number of consumers and states would be conducted to better understand the role of flavor. However, conducting such a sensory survey is expensive compared with an online survey and most likely would not constitute a random sample of consumers. Given many consumers have an idea what an astringent/bitter flavor tastes like, the online survey allows for a relatively large sample where inferences can be made about how respondents would respond to a generic taste message provided with aronia berries. Other studies eliciting consumer preference for sensory attributes based on an online survey include Chung et al. (2011) and Moskowitz and Silcher (2006) to name a few. Treatment three (T3) consisted of health information indicating that aronia berries have high levels of antioxidants which are two to four times higher than acai berry, goji berry, wild blueberries, and cranberries. Treatment four (T4) was a combination of T2 and T3. The purpose of the treatments was to assess the impact of a nonsweet berry taste and health information on consumer preference and WTP. Furthermore, we wanted to examine whether positive health information would mitigate the impact of potentially negative taste information.

On beginning the $\mathrm{CE}$, participants were asked to treat the experiment like a real purchasing situation while also being reminded of their budget constraint. Within each choice set, a different berry product was shown with the information corresponding to each specific product based on the experimental design specification. The ordering of choice sets and choices within each set was randomized for each respondent.

Model estimation. Heterogeneous taste and preferences across consumers are a concern when estimating preferences (Greene and Hensher, 2003). Conditional logit is often used for $\mathrm{CE}$ but it does not account for heterogeneity among consumers and imposes the independent of irrelevant alternatives assumption (Hole, 2013). Therefore, we use the Random Parameters Logit (RPL) model to account for possible consumer heterogeneity by allowing some of the model parameters to be randomly distributed (Hole, 2013). As noted by Hensher et al. (2005), the utility function for the RPL model can be formulated as:

$$
U_{j s i}=\sum_{k=1}^{K} \beta_{i k} x_{j s i k}+\varepsilon_{j s i}
$$

where $x_{j s i k}$ are explanatory variables such as attributes in choice task $i$ and $\beta_{\mathrm{ik}}$ and $\varepsilon_{\mathrm{jsi}}$ are unobserved and stochastic with $\varepsilon_{\mathrm{jsi}}$ representing independent and identically distributed errors (i.i.d.). Errors may not be i.i.d. for a number of reasons, but most importantly for our model is due to clustered data (i.e., correlation within choices of a consumer, but independent across consumers). However, the RPL model clusters on each consumers limiting the potential for a violation of i.i.d. From each choice set, respondents choose the product that maximizes utility. To assess the impact of the informational treatments and state effects, interaction terms were added to the model such that utility could be defined as:

$$
\begin{aligned}
\mathrm{U}_{\mathrm{jsi}}= & \beta_{1}+\beta_{2} \text { No purchase }+\beta_{3} \text { Local FM } \\
& +\beta_{4} \text { Local FS }+\beta_{5} \text { Regional GS } \\
& +\beta_{6} \text { U.S. GS }+\beta_{7} \text { Outside U.S. GS } \\
& +\beta_{8} \text { Aronia }+\beta_{9} \text { Raspberry } \\
& +\beta_{10} \text { Blackberry } \\
& +\beta_{11} \text { BlackCurrant }+\beta_{12} \text { Organic } \\
& +\beta_{13} \text { Aronia } * \mathrm{~T} 2+\beta_{14} \text { Aronia } * \mathrm{~T} 3 \\
& +\beta_{15} \text { Aronia } * \mathrm{~T} 4+\beta_{16} \text { Aronia } * \mathrm{NH} \\
& +\beta_{17} \text { Aronia } * \mathrm{NJ}+\beta_{18} \text { Aronia } * \mathrm{PA} \\
& +\beta_{19} \text { Aronia } * \mathrm{RI}+\beta_{20} \text { Aronia } * \mathrm{VT} \\
& +\beta_{21} \text { Aronia } * \mathrm{CT}+\beta_{22} \text { Aronia } * \mathrm{ME} \\
& +\beta_{23} \text { Aronia } * \mathrm{MA}+\varepsilon_{\mathrm{jsi}}
\end{aligned}
$$

where $\mathrm{FM}=$ farmer's market, $\mathrm{FS}=$ farm stand, and GS = grocery store. Of particular interest are the interaction effects between treatment and aronia. Of note, awareness and/ or purchasing of aronia berries could impact the effect of the treatments. To assess how awareness or past purchasing might impact the treatment effect, we included awareness as well as past aronia purchasing interactions with aronia and treatments. Results of these interactions were not significant in a variety of model specifications, therefore, we do not include the interactions in the final model.

WTP was calculated for each attribute without an interaction as:

$$
\mathrm{WTP}_{i k}=-\left(\frac{\beta_{i k}}{\beta_{p}}\right)
$$

where $\beta_{i k}$ is the coefficient for the attribute level of interest and $\beta_{p}$ is the coefficient for price (Louviere et al., 2000). For attribute levels with interactions, WTP was calculated as:

$$
\mathrm{WTP}_{i k}=-\left(\frac{\beta_{i k}+\beta\left({ }_{n}\right)(\mathrm{D})}{\beta_{p}}\right)
$$

where $\beta_{i k}$ is the coefficient for the $k^{\text {th }}$ attribute level plus, $\beta\left({ }_{n}\right)$ is the coefficient value of the $n^{\text {th }}$ interaction that corresponds to the $k^{\text {th }}$ attribute level times the interacted dummy.
Standard errors for the WTP estimates were calculated via Delta Method. WTP values for each treatment were compared by examining overlap within the confidence intervals.

\section{Results and Discussion}

Results from the RPL model can be found in Table 3. Consistent with economic theory, the price attribute displays the expected negative sign $(-0.794)$ indicating the consumers within our sample preferred lower prices to higher prices. Furthermore, the none of the above choice had a significant negative coefficient $(-3.912)$ indicating that a consumer would have received disutility by selecting the none of the above option within a choice set.

Berry results. Blueberries were the most preferred berry followed by raspberries and blackberries (Table 3). This is consistent with DiMartino (2015) that denote blueberries are the second most popular berry in the United States behind strawberries with raspberries being the third most popular. The berries that consumers were less familiar with, black currant and aronia, were the least preferred. The preference toward the more traditional berries is most likely due to consumers being risk adverse in trying new berry varieties.

Treatment interactions. Aronia berries are a relatively new berry to the U.S. market and are competing with several well-established berries such as blueberries, blackberries, and raspberries. All of the competing berries are sweet tasting berries that have been bred over many years to enhanced sweetness (Clark, 2005). However, the taste profile for aronia is bitter/astringent. As expected, providing taste information (T2) caused a decrease in preference compared with the other treatments (Table 3). Positive health information (T3) provides a significantly positive preference gain while the full information treatment (T4) is similar to the no information treatment (T1). Given these results, it seems that supplying only health information would have the best effect on consumer preference. However, consumers will most likely not want to purchase an astringent/bitter berry without being informed or could have buyer's remorse if they purchase a berry that is not what they expect, thereby, taste information should be provided. In providing the taste information it should be combined with health information so that the health information can offset the negative taste information. From a marketing perspective, producers and/or retailers of aronia berries should consider providing both taste and health information instead of only taste information.

State interactions. The state/aronia interaction indicates that most all states throughout the Northeast have similar preferences for aronia (Table 3). This is most likely due to aronia being a relatively unknown berry within this region. The only exception is Maine which has a lower preference for aronia compared with all the other Northeastern states. 
Retail outlet and organic production. Examining location of purchase we find that a locally labeled berry at a farmer's market and farm stand are preferred the same as a locally labeled berry from a grocery store (Table 3 ). However, all the locally labeled berries, regardless of retail outlet, are preferred to nonlocally labeled berries. For nonlocal berries, regional berries are preferred to U.S. berries and U.S. berries are preferred to berries produced outside the United States. These results are somewhat consistent with our hypothesis in that local berries would be preferred to nonlocal berries. However, our hypothesis that local berry labeling would be dependent on retail outlet was not confirmed. Notably, we find equivalent WTP for locally grown berries at farmer's markets, farm stands, and grocery stores. With respect to organic, we find that organic berries were preferred to nonlabeled berries.

Marginal WTP: Berries. Overall, aronia berries experienced a $\$ 3.46$ discount in WTP compared with blueberries (Table 4). The \$3.46 WTP is equivalent to the no information treatment (T1). The discount associated with black currant was $\$ 2.90$ compared with blueberries. Both the aronia and black currant WTP values are significantly different from raspberry, blackberry, and blueberries. There is slight overlap of the confidence intervals between aronia and black currant WTP so we cannot definitively say the WTP values are significantly different, but given there is only a small overlap a difference most likely exists. Raspberries and blackberries had similar discounts in WTP that were significantly lower than what a consumer would pay for blueberries.

Marginal WTP: Information treatments. The WTP for aronia berries when no information (T1) is provided was $-\$ 3.46$ compared with blueberries, but the introduction of aronia taste information (T2) resulted in a discounted WTP of $-\$ 4.35$ or a $26 \%$ decrease from the WTP in T1 (Table 5). When health information alone was provided (T3) WTP improved by $15 \%$ to only $\$ 2.94$ less than blueberries with no information and a $32 \%$ increase compared with $\mathrm{T} 2$. Introducing both taste and health information (T4) provided a statistically similar WTP to T1. From a retailing perspective it is clear that producers/retailers marketing aronia berries should provide information to their consumers to increase preference and WTP. Based solely on our estimates retailers should provide only the health information about aronia berries. However, many retailers may wish to discuss the flavor of aronia berries with potential customers in the interest of providing full information. If retailers provide taste information they should also provide health information to increase preference and WTP.

Marginal WTP: Retail location and organic. Consumers were WTP $\$ 0.27, \$ 0.65$, and $\$ 1.47$ more per eight ounce container of locally grown berries at a grocery store compared with regional, U.S.-grown, and outside U.S.-grown berries, respectively (Table 6). With respect to organic, consumers within our

Table 3. Random parameter logit (RPL) model results based on a choice based experiment of Northeastern U.S. consumers administered during 2013.

\begin{tabular}{|c|c|c|}
\hline Variable & RPL coefficients & $P$ value \\
\hline \multicolumn{3}{|c|}{ Means of the random parameters in utility functions } \\
\hline None of the above & -3.912 & 0.000 \\
\hline \multicolumn{3}{|l|}{ Location } \\
\hline Local berry at farmer's market & 0.056 & 0.432 \\
\hline Local berry at farm stand & 0.097 & 0.213 \\
\hline Local berry at grocery store & - & - \\
\hline Base: regional berry at grocery store & -0.218 & 0.002 \\
\hline U.S. berry at grocery store & -0.515 & 0.000 \\
\hline Outside U.S. berry at grocery store & -1.171 & 0.000 \\
\hline \multicolumn{3}{|l|}{ Berry } \\
\hline Aronia & -2.751 & 0.000 \\
\hline Raspberry & -0.736 & 0.000 \\
\hline Blackberry & -0.894 & 0.000 \\
\hline Black currant & -2.301 & 0.000 \\
\hline Base: blueberry & - & - \\
\hline \multicolumn{3}{|l|}{ Organic } \\
\hline Yes & 0.139 & 0.001 \\
\hline Base: no & - & - \\
\hline \multicolumn{3}{|l|}{ Nonrandom parameters in the utility functions } \\
\hline Price & -0.794 & 0.000 \\
\hline \multicolumn{3}{|l|}{ Aronia $\times$ treatment interaction } \\
\hline Aronia $\times$ taste information & -0.701 & 0.002 \\
\hline Aronia $\times$ health information & 0.416 & 0.051 \\
\hline Aronia $\times$ control & - & - \\
\hline Aronia $\times$ taste/health information & 0.103 & 0.621 \\
\hline \multicolumn{3}{|l|}{ Aronia $\times$ state interaction } \\
\hline Aronia $\times$ New York & - & - \\
\hline Aronia $\times$ New Hampshire & 0.495 & 0.321 \\
\hline Aronia $\times$ New Jersey & 0.052 & 0.850 \\
\hline Aronia $\times$ Pennsylvania & -0.010 & 0.967 \\
\hline Aronia $\times$ Rhode Island & -0.425 & 0.465 \\
\hline Aronia $\times$ Vermont & 0.892 & 0.105 \\
\hline Aronia $\times$ Connecticut & 0.151 & 0.555 \\
\hline Aronia $\times$ Maine & -1.080 & 0.009 \\
\hline Aronia $\times$ Massachusetts & 0.111 & 0.683 \\
\hline \multicolumn{3}{|c|}{ Derived standard deviations of parameter distributions } \\
\hline None & 2.007 & 0.000 \\
\hline Local berry at farmer's market & 0.987 & 0.000 \\
\hline Local berry at farm stand & 1.168 & 0.000 \\
\hline Local berry at grocery store & 0.182 & 0.029 \\
\hline U.S. berry at grocery store & 0.209 & 0.005 \\
\hline Outside U.S. berry at grocery store & 0.541 & 0.000 \\
\hline Aronia & 2.592 & 0.000 \\
\hline Raspberry & 2.130 & 0.000 \\
\hline Blackberry & 1.635 & 0.000 \\
\hline Black currant & 2.389 & 0.000 \\
\hline Organic: yes & 0.319 & 0.000 \\
\hline
\end{tabular}

Bold text indicates significance at the $10 \%$ level.

- denotes the variable was the base category.

Table 4. Northeastern U.S. consumer willingness to pay for several berry varieties.

\begin{tabular}{lcccc}
\hline & & & \multicolumn{2}{c}{ Confidence interval } \\
\cline { 3 - 5 } Variable & Willingness to pay $(\$)$ & $P$ value & Lower limit & Upper limit \\
\hline Aronia & $\mathbf{- 3 . 4 6}$ & 0.000 & -4.05 & -2.88 \\
Raspberry & $\mathbf{- 0 . 9 3}$ & 0.000 & -1.13 & -0.73 \\
Blackberry & $\mathbf{- 1 . 1 3}$ & 0.000 & -1.31 & -0.94 \\
Black currant & $-\mathbf{2 . 9 0}$ & 0.000 & -3.19 & -2.61 \\
Blueberry & - & - & - & - \\
\hline
\end{tabular}

Bold text indicates significance at the $10 \%$ level.

- denotes the variable was the base category.

sample were WTP a \$0.18 per half-pint premium for organically produced berries (Table $5)$. These results were expected given the trends toward local and organic products within the market.

\section{Conclusion}

As producers look to market new berry varieties, it is essential for these producers and retailers to understand how information will impact preference and WTP for these new varieties. Using a novel berry with a nonsweet flavor, we examine how taste and health information can impact preference and WTP. We find that positive health information can increase preference vs. no information, but taste information can have a negative effect on preference. Furthermore, we find that health information can 
Table 5. Northeastern U.S. consumer willingness to pay for varying informational treatments associated with berries.

\begin{tabular}{lcccc}
\hline & & & \multicolumn{2}{c}{ Confidence interval } \\
\cline { 5 - 6 } Variable & Willingness to pay $(\$)$ & $P$ value & Lower limit & Upper limit \\
\hline Control & - & - & - & - \\
Taste $\times$ aronia & $\mathbf{- 4 . 3 5}$ & 0.000 & -5.03 & -3.66 \\
Health $\times$ aronia & $\mathbf{- 2 . 9 4}$ & 0.000 & -3.58 & -2.31 \\
Taste $/$ health $\times$ aronia & $-\mathbf{3 . 3 3}$ & 0.000 & -3.92 & -2.75 \\
\hline
\end{tabular}

Bold text indicates significance at the $10 \%$ level.

- denotes the variable was the base category.

Table 6. Northeastern U.S. consumer willingness to pay for local and organic berry attributes.

\begin{tabular}{lcccc}
\hline & & & \multicolumn{2}{c}{ Confidence interval } \\
\cline { 4 - 5 } Variable & Willingness to pay $(\$)$ & $P$ value & Lower limit & Upper limit \\
\hline Local at farmer's market & 0.07 & 0.432 & -0.11 & 0.25 \\
Local at farm stand & 0.12 & 0.212 & -0.07 & 0.31 \\
Local at grocery store & - & - & - & - \\
Regional at grocery store & $\mathbf{- 0 . 2 7}$ & 0.002 & -0.45 & -0.10 \\
U.S. at grocery store & $\mathbf{- 0 . 6 5}$ & 0.000 & -0.81 & -0.48 \\
Outside U.S. at grocery store & $\mathbf{- 1 . 4 7}$ & 0.000 & -1.69 & -1.26 \\
Organic & $\mathbf{0 . 1 8}$ & 0.001 & 0.07 & 0.28 \\
\hline
\end{tabular}

Bold text indicates significance at the $10 \%$ level.

- denotes the variable was the base category.

potentially offset the negative impact of an astringent/bitter flavored berry. For marketers of aronia berries, this is an important finding, as health information can be used to counter any potential negative implications of an astringent/bitter flavor.

However, central to these findings is that aronia, and black currant, were significantly less preferred than the other berries. Even when displaying health information consumers will gravitate to the more well-known berry varieties implying pricing will be critical for aronia producers that are competing producers/retailers of other berries on the market. For instance, a $\$ 4.00$ priced blueberry container implies the eight ounce aronia container would need to be priced at $\$ 0.47$ to be comparable in preference to the blueberry container. The addition of taste information would mean the average consumer would not purchase aronia, but taste information only would imply a $\$ 1.06$ price per container would make consumers indifferent between blueberry and aronia containers. From an aronia producer perspective, producers should evaluate their markets and price according to who their competitors are given consumers value blueberries at a premium while competing only against blackberries, raspberries, or black currant could allow for higher pricing per eight ounce container.

Furthermore, as retailers and policymakers attempt to increase local purchasing, it is essential to understand consumer preference at varying retail outlets. Our results show that there are price premiums for locally grown berries compared with nonlocally labeled berries. However, the local berry premiums are the same across various retail outlets (farmer's markets, farm stands, and grocery stores). From a retailer perspective, outlets selling berries should be cognizant of their pricing strategies for local berries as assuming WTP premiums due to type outlet may be a mistake.
This study serves as a first step to understand consumer preference and WTP for aronia berries given competing berries and varying information. However, other studies are needed to have a complete picture of the aronia berry market, including demand and consumer segments for aronia berries, agronomic production costs, and sensory testing. Studies of this nature will provide more information for producers and retailers to make better decisions.

\section{Literature Cited}

Beck, M.A. 2014. Aronia berry gaining market foothold in U.S. USA Today. 5 June 2016. $<$ http://www.usatoday.com/story/money/business/ 2014/07/12/aronia-berry-gaining-market-footholdin-us/12571761/>.

Carroll, A.K., C.J. Bernard, and D.J. Pesek. 2013. Consumer preferences for tomatoes: The influence of local, organic, and state program promotions by purchasing venue. J. Agr. Resour. Econ. 38(3):379-396.

Chaker, A.M. 2013. “America's Next Top Super Berry?" The Wall Street Journal. 19 July 2016. <http://www.wsj.com/articles/ SB100014241278873238230045785956100770 $83082>$.

Chung, H.S., H. Hong, K. Kim, C. Cho, H.R. Moskowitz, and S. Lee. 2011. Consumer attitudes and expectations of ginseng food products assessed by focus groups and conjoint analysis. J. Sens. Stud. 26(5):346-357.

Clark, J.E. 1998. Taste and flavor: Their importance in food choice and acceptance. Proc. Nutr. Soc. 57:639-643.

Clark, J.R. 2005. Changing times for eastern United States blackberries. HortTechnology 15:491-494.

Cobanoglu, C., B. Warde, and P.J. Moreo. 2001. A comparison of mail, fax and web-survey methods. Intl. J. Mktg. Res. 43:441-452.

Cook, L.R. 2012. Three part series: Fundamental forces affecting growers and marketers. Eye on Economics of Berries. 15 May 2014. <http:// ucce.ucdavis.edu/files/datastore/234-2421.pdf>.

Cranage, D.A., M.T. Conklin, and P.L. Bordi. 2003. Can young adults be influenced to eat healthier snacks: The effects of choice and nutritional information on taste, satisfaction and intent to purchase. J. Foodservice 14 (2): $125-137$.

Darby, K., M.T. Batte, S. Ernst, and B. Roe. 2008. Decomposing local: A conjoint analysis of locally produced foods. Amer. J. Agr. Econ. 90(2):476-486.

DiMartino, C. 2015. In the know: U.S. berry demand and imports. The Produce News. 15 Aug. 2016. $<\mathrm{http}: / /$ theproducenews.com/ markets-and-trends/8784-in-the-know-u-s-berrydemand-and-imports $>$.

Dillman, D., J. Smyth, and L. Christian. 2009. Internet, Mail, and Mixed-Mode Surveys: The Tailored Design Method. John Wiley \& Sons, Inc., Hoboken, NJ.

DiMartino, C. 2016. Growing consumer demand supports increasing berry imports. The Produce News. 4 Dec. 2016. <http://www. producenews.com/markets-and-trends/19699growing-consumer-demand-supports-increasingberry-imports $>$.

Everhart, E. 2011. Where is aronia grown? Aronia in America. 26 Nov. 2016.<http://aroniainamerica. blogspot.com/2011/03/where-is-aronia-growncommercially.html>.

Fong, P. 2013. Aronia berries. Men's Journal. 3 June 2016. <http://www.mensjournal.com/healthfitness/nutrition/the-next-big-berry-20130426>.

Gagliardi, N. 2015. Consumers want healthy foods: And will pay more for them. Forbes. 2 Dec. 2016. <http://www.forbes.com/sites/ nancygagliardi/2015/02/18/consumers-wanthealthy-foods-and-will-pay-more-for-them/ \#73b6814b144f>.

Greene, W.H. and D.A. Hensher. 2003. Modeling Ordered Choices. Cambridge University Press, New York, NY.

Hannan, J.M. 2013. Aronia berries. Agricultural Marketing Resource Center. 27 Nov. 2016. $<$ http://www.agmrc.org/commodities-products/ fruits/aronia-berries/>.

Hensher, D.A., J.M. Rose, and W.H. Greene. 2005. Applied choice analysis: A primer. Cambridge University Press, New York, NY.

Hole, A.R. 2013. Mixed logit modelling in Stata UK Stata Users Group meeting. 5 Dec. 2016. $<\mathrm{http} / / /$ www.stata.com/meeting/uk13/abstracts/ materials/uk13_hole.pdf $>$.

Hu, W., M.T. Batte, T. Woods, and S. Ernst. 2012. Consumer preferences for local production and other value-added label claims for a processed food product. Eur. Rev. Agr. Econ. 39(3):489510 .

Hu, W., T. Woods, and S. Bastin. 2009. Consumer acceptance and willingness to pay for blueberry products with nonconventional attributes. J. Agr. Appl. Economics 41(1):47-60.

Janssen, M. and U. Hamm. 2012. Product labelling in the market for organic food: Consumer preferences and willingness-to-pay for different organic certification logos. Food Qual. Prefer. 25:9-22.

Kennell, B. 2016. Healthy food trends drive new products. The Huffington Post. 2 Dec. 2016. $<\mathrm{http}$ ://www.huffingtonpost.com/brian-kennell/ healthy-food-trends-drive_b_8222388.html $>$.

Kilham, C. 2013. Aronia: The North American super berry with cancer-fighting properties. Fox News. 5 June 2016. <http://www.foxnews. com/health/2013/06/07/aronia-north-americansuper-berry-with-cancer-fighting-benefits/>.

Kuhfeld, W.F. 2010. Marketing research methods in SAS: Experimental design, choice, conjoint, and graphical techniques. 5 May 2016. <http://support. sas.com/techsup/technote/mr2010.pdf $>$.

Lawless, L.J.R., R.M. Nayga, Jr., F. Akaichi, J. Meullenet, R.T. Threlfall, and L.R. Howard. 
2012. Willingness to pay for a nutraceuticalrich juice blend. J. Sens. Stud. 27(5):375-383.

Lim, K.H. and W. Hu. 2015. How local is local? A reflection on Canadian local food labeling policy from consumer preference. Can. J. Agr. Econ. 64(1):71-88.

Louviere, J.J., D.A. Hensher, and J.D. Swait. 2000. Stated choice methods: Analysis and application. Cambridge University Press, Cambridge, UK.

McCullough, D. 1998. Web-based market research: The dawning of a new age. Direct Mktg. 61:36-38.

McFarlane, T. and P. Pliner. 1997. Increasing willingness to taste novel foods: Effects of nutrition and taste information. Appetite 28 (3):227-238.

McKay, S.A. 2001. Demand increasing for aronia and elderberry in North America. New York Fruit Qrtly. 9(3):2-3.

Mohebalian, P.M., M.M. Cernusca, and F.X. Aguilar. 2012. Discovering niche markets for elderberry juice in the United States. HortTechnology 22:556-566.

Mohebalian, P.M., M.M. Cernusca, and F.X. Aguilar. 2013. Conjoint analysis of U.S. consumers' preference for elderberry jelly and juice products. HortScience 48:338-346.
Monroe, K.B. 1976. The influence of price differences and brand familiarity on brand preferences. J. Consum. Res. 3:42-49.

Moskowitz, H.R. and M. Silcher. 2006. The applications of conjoint analysis and their possible uses in Sensometrics. Food Qual. Prefer. 17(34):145-165.

Onozaka, Y. and D.T. McFadden. 2011. Does local labeling complement or compete with other sustainable labels? A conjoint analysis of direct and joint values for fresh produce claims. Amer. J. Agr. Econ. 93(3):693-706.

Roosen, J., S. Marette, S. Blanchemanche, and P. Verger. 2007. The effect of product health information on liking and choice. Food Qual. Prefer. 18(5):759-770.

Shi, L., L.A. House, and Z. Gao. 2013. Impact of purchase intentions on full and partial bids in BDM auctions: Willingness-to-pay for organic and local blueberries. J. Agr. Econ. 64(3):707-718.

Steiner, J.E. 1977. Facial expressions of the neonate infant indicating the hedonics of food related chemical stimuli, p. 173-189. In: J.M. Weiffenbach (ed.). Taste and development: The genesis of sweet preference. DHEW Publication no. NIH 77-1068, U.S. Government Publishing Office, Washington, DC.
The Nielson Company. 2015. The state of fresh: Are fresh foods really stealing sales from non- fresh foods? 15 Aug. 2016. <http://www.nielsen.com/ us/en/insights/news/2015/the-state-of-fresh-arefresh-foods-really-stealing-sales-from-non-freshfoods.html $>$.

Train, K. 2009. Discrete choice methods with simulation. 2nd ed. Cambridge University Press.

U.S. Census Bureau. 2011. 2010 census shows nation's population is aging. 10 Aug. 2016. $<$ https://www.census.gov/newsroom/releases/ archives/2010_census/cb11-cn147.html $>$.

U.S. Census Bureau. 2014. State and county quickfacts. 15 May 2016. <http://quickfacts. census.gov/qfd/index.html>.

USDA Economic Research Service. 2014. Food availability (per capita) data system. 12 May 2016. <https://www.ers.usda.gov/data-products/ food-availability-per-capita-data-system/>.

Wang, J., C. Yue, K. Gallardo, V. McCracken, J. Luby, and J. McFerson. 2016. What consumers are looking for in strawberries: Implications from market segmentation analysis. Agribusiness: Intl. J. doi:10.1002/agr.21473.

World Bank. 2013. Internet users (per 100 people). 9 May 2016. <http://data.worldbank.org/ indicator/IT.NET.USER.P2>. 